\title{
Analyzing the Pam's Structure USING The ISO/IEC 15504-5 STANDARD (SPICE)
}

\author{
KOZINA, M. \& KIRINIC, V.
}

Abstract: Considering the previous studies that point to problems in the software process development (high costs, low productivity of development team, low usability, etc.), we conclude that the causes of the problem should be solved in the processes that produce the final result. Process quality directly affects the quality of the product. The purpose of the paper is to present the ISO/IEC 15504 standard and analyze the structure of the process assessment model (PAM) within the ISO/IEC 15504-5 standard (SPICE model).The authors in the paper analyzed the obtained results based on the conducted assessment using SPICE model within the specific software organization. Based on this research, the authors emphasize the need for further development of such a model, not only for the software but also for complex IT systems as well as IT services.

Key words: ISO/IEC 15504 standard, PAM's structure for software (SPICE), assessment of the process capabilities using SPICE
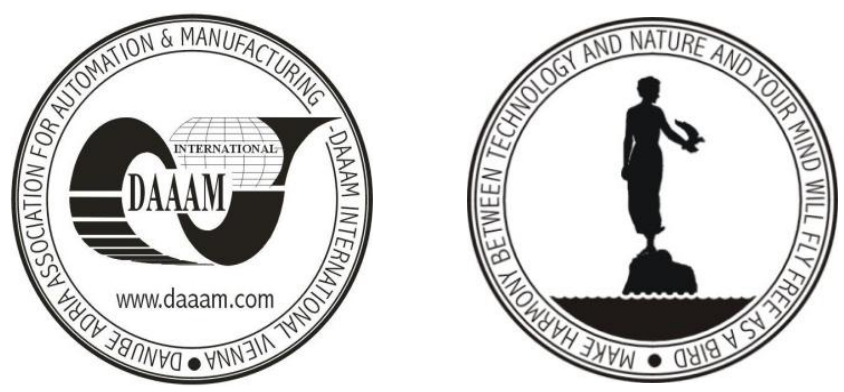

Authors' data: Prof.dr.sc. Kozina, M[elita]; Doc. dr. sc. Kirinic, V[alentina], University of Zagreb, Faculty of organization and informatics, Pavlinska 2, 42000, Varazdin, Croatia, melita.kozina@foi.hr, valentina.kirinic@foi.hr

This Publication has to be referred as: Kozina, M[elita] \& Kirinic, V[alentina] (2013) Analyzing the Pam's Structure Using the Iso/Iec 15504-5 Standard (Spice), Chapter 26 in DAAAM International Scientific Book 2013, pp. 475-490, B. Katalinic \& Z. Tekic (Eds.), Published by DAAAM International, ISBN 978-3-901509-94-0, ISSN 1726-9687, Vienna, Austria

DOI: 10.2507/daaam.scibook.2013.26 
Kozina, M. \& Kirinic, V.: Analyzing the Pam's Structure Using the Iso/Iec 15504-5...

\section{Introduction}

In the information society based on knowledge, innovation and intensive application of information and communication technologies (ICT), software is a key factor in modern business. What is the problem? Many studies indicate that the quality of software is very often questionable, given the low productivity of development teams, low usability of software, high maintenance costs, etc. The important strategic goal for the software organizations is how to improve the quality of software by applying standards, methods, models, tools for quality and successful development and management of a software product (O'Regan, 2011).

What is done by other researchers to address the problem of poor software quality? Software Process Improvement (SPI) is an approach to software quality improvement based on the basic concept of the process improvements developed by Walter Shewhart, W. Edwards Deming, Philip Crosby, Joseph Juran, Watts Humphrey and other researchers. According to Humphrey, the software development process is a set of practices, methods and tools that produce the software product and this process must be predictable and continuously improved. However, there are different models of SPI, which began to develop at the end of 80 such as CMM, Bootstrap, Bootcheck, SPICE, Trillium, etc. Each of them has its own procedural rules or practices, their methods and approaches to assess maturity and improvement so it is quite difficult to apply a single model/standard in the software organization in order to improve the software development process.

ISO/IEC 15504-5 (SPICE model) as well as Capability Maturity Model Integration (CMMI) are modern SPI models that offer the possibility of integration of the best practice for the software development and approaches for the process capability assessment and the relevant improvements. In compliance with this, the reason for our research is to analyze the Process Assessment Model (PAM) for software using the ISO/IEC 15504-5 standard (described in the Chapter 3) and apply this model to assess the process capabilities within specific software organization (described in the Chapter 4).

The assessment was conducted for the Primary Life Cycle processes, Organizational Life Cycle processes and Supporting Life Cycle processes of the organization. According to the obtained results of our research, we can conclude that the whole organizational maturity level is no greater then 2 - Managed Level: the processes execute their purposes (Level 1) and manage their execution (each of the processes is planned, monitored, adjusted). The organization should implement improvements in all processes, especially in the Organizational Life Cycle processes and achieve the organizational maturity at least level 3 - Defined Level: managed processes (Level 2) are now implemented as defined and documented and they are able to achieve the work results. Capability Level (CL) refers to the ability of the process, and the Maturity Level (ML) of the overall organization.

The applied PAM's structure (SPICE model) within our research is very effective since it integrates the best practices based on integrated process and product development as well as the approaches for the maturity assessment of these practices. Accordingly, it is possible to determine the required improvements for the software 
development. However, the implementation of generic practices and improvements need to invest a lot of resources and it is very expensive. The management support is very important in this decision making process.

The authors emphasize the need for further development of such a model, not only for the software but also for complex IT systems as well as IT services.

\section{ISO/IEC 15504 standard}

ISO/IEC 15504 is an International Standard for Process Assessment that was initiated in 1993 as the SPICE (Software Process Improvement and Capability Determination) model. ISO/IEC 15504 was developed by JTC1/SC7's Working Group. The origins for the development of the ISO/IEC 15504 were the ISO/IEC standard Information technology - Software life cycle processes (ISO/IEC TR 12207:1995) and the maturity models such as Bootstrap, Trillium and the CMM (shown in Fig.1).

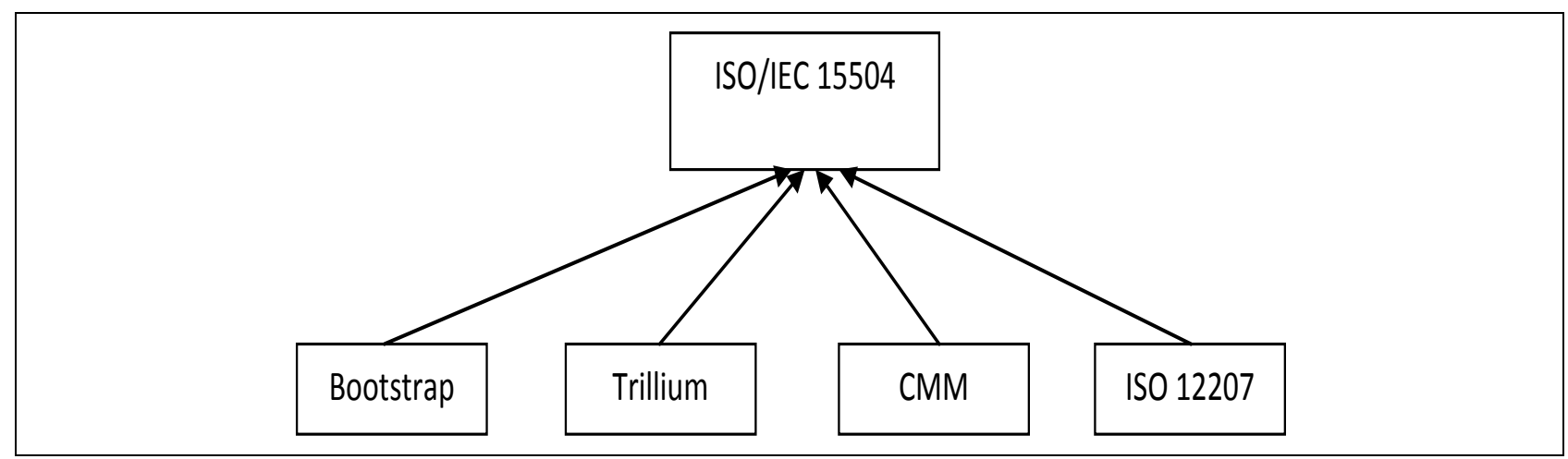

Fig. 1. The origin for the development of ISO/IEC 15504

Current version of the ISO/IEC 15504 standard is shown in Tab.1.

\begin{tabular}{|l|l|}
\hline ISO/IEC 15504 & Title \\
\hline ISO/IEC 15504-1:2004 & $\begin{array}{l}\text { Information technology - Process assessment - Part 1: Concepts and } \\
\text { vocabulary }\end{array}$ \\
\hline $\begin{array}{l}\text { ISO/IEC 15504-2:2003 } \\
\text { (Cor 1:2004) }\end{array}$ & $\begin{array}{l}\text { Information technology - Process assessment - Part 2: Performing an } \\
\text { assessment }\end{array}$ \\
\hline ISO/IEC 15504-3:2004 & $\begin{array}{l}\text { Information technology - Process assessment - Part 3: Guidance on } \\
\text { performing an assessment }\end{array}$ \\
\hline ISO/IEC 15504-4:2004 & $\begin{array}{l}\text { Information technology - Process assessment - Part 4: Guidance on use for } \\
\text { process improvement and process capability determination }\end{array}$ \\
\hline $\begin{array}{l}\text { ISO/IEC 15504-5:2012 } \\
\text { (SPICE model) }\end{array}$ & $\begin{array}{l}\text { Information technology - Process assessment - Part 5: An exemplar } \\
\text { software life cycle process assessment model }\end{array}$ \\
\hline ISO/IEC TR 15504-6:2008 & $\begin{array}{l}\text { Information technology - Process assessment - Part 6: An exemplar system } \\
\text { life cycle process assessment model }\end{array}$ \\
\hline ISO/IEC TR 15504-7:2008 & $\begin{array}{l}\text { Information technology - Process assessment - Part 7: Assessment of } \\
\text { organizational maturity }\end{array}$ \\
\hline ISO/IEC TS 15504-8:2012 & $\begin{array}{l}\text { Information technology - Process assessment - Part 8: An exemplar } \\
\text { process assessment model for IT service management }\end{array}$ \\
\hline ISO/IEC TS 15504-9:2011 & $\begin{array}{l}\text { Information technology - Process assessment - Part 9: Target process } \\
\text { profiles }\end{array}$ \\
\hline ISO/IEC TS 15504-10:2011 & Information technology - Process assessment - Part 10: Safety extension \\
\hline
\end{tabular}

Tab.1. The ISO/IEC 15504 standard 
Kozina, M. \& Kirinic, V.: Analyzing the Pam's Structure Using the Iso/Iec 15504-5...

The purpose of the ISO/IEC 15504 standard for process assessment is to determine the process capability as a basis for the process improvement (ISO/IEC TR 15504-1:1998(E)) (shown in Fig.2).

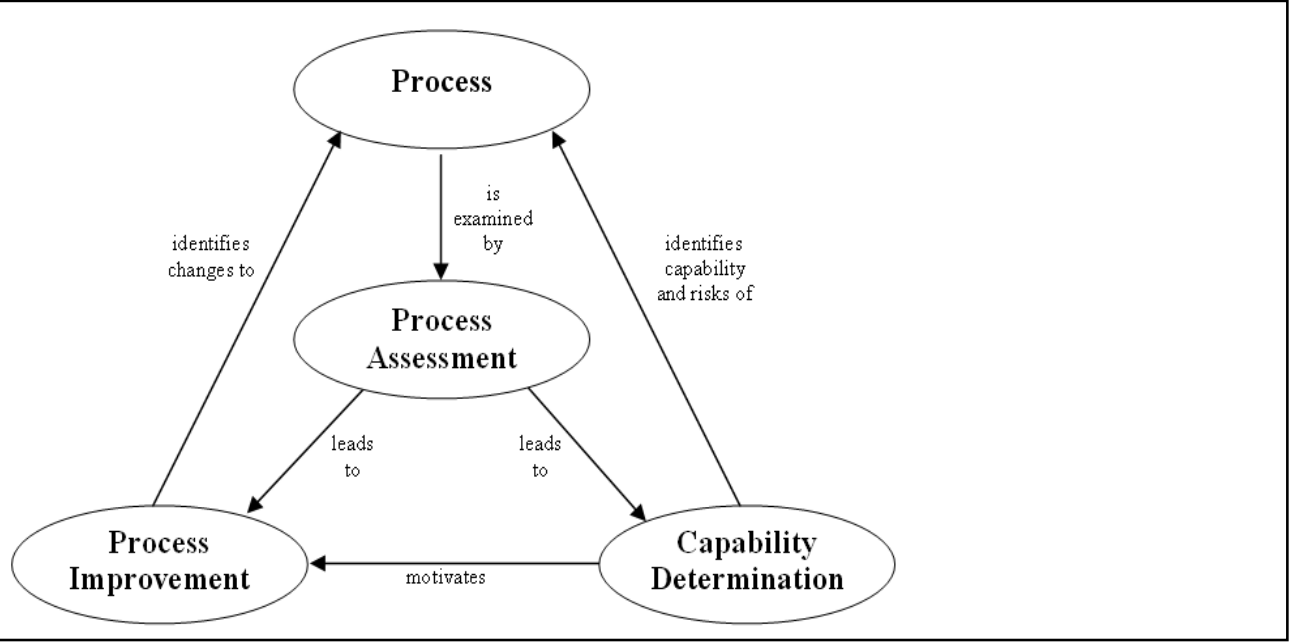

Fig. 2. Process Assessment according to ISO/IEC TR 15504-1:1998

In the context of determining the process capability there is a need to analyze the capability of the selected processes due to the target level of capability and thereby identify risks and their reduction.

In the context of process improvement is very important the following:

- to analyze the business goals and the objectives for quality performance of processes in the organization;

- to analyze the causes of poor performance based on the assessment of the existing level of process capabilities;

- to define the proposals for the process changes and improvements.

ISO/IEC 15504-2 specifies requirements for Process Reference Models (PRM), Process Assessment Models (PAM) and process assessment methods as well as defining a measurement framework for process capability (ISO/IEC TR 155042:1998(E); Sassenburg \& Kitson, 2006). It is shown in Fig.3.

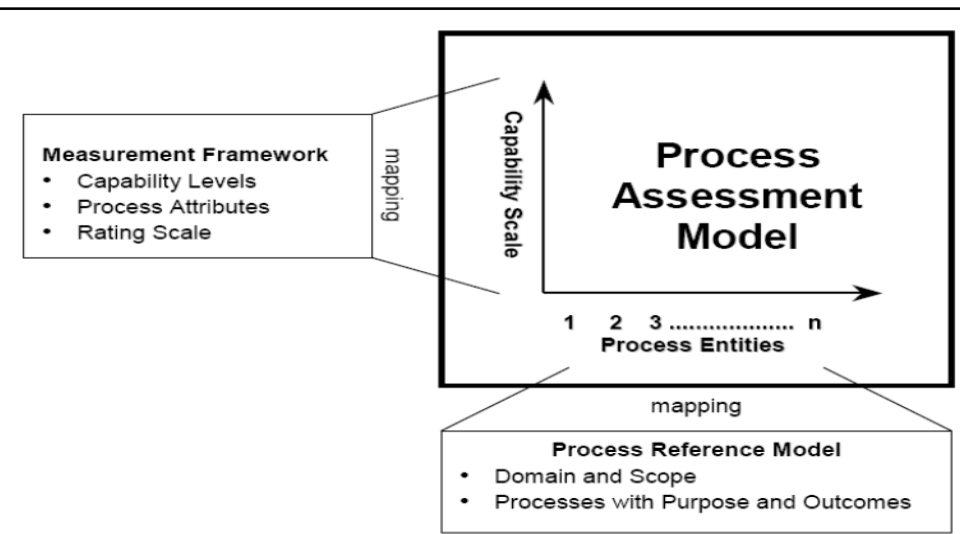

Fig. 3. PAM's structure according to ISO/IEC 15504-2 (Sassenburg \& Kitson, 2006) 
The PAM's concept according to ISO/IEC 15504-2 includes two dimensions: process dimension and capability dimension (measurement framework). The process dimension is related to the concept of the Process Reference Model (PRM). A PRM defines processes in terms of a purpose statement and one or more outcomes/achievements that should be satisfied when the process is performed. It is important in order to achieve the purpose of the process or the relevant process capability. Part 5 of the ISO/IEC 15504 exists as a software PAM (SPICE model) using the amended version of ISO/IEC 12207 as its PRM.

The second PAM's dimension is related to the measurement framework for the process capability assessment through the process attributes and the relevant capability levels (incomplete, performed, managed, established, predictable and optimizing). PAM also contains indicators (such as work products, resources, base practices, etc.) used in the assessment process in order to determine the process attribute rating for each process. Each attribute must be rated on a scale from Not achieved through Fully achieved.

\subsection{Documented assessment process according to ISO/IEC 15504}

ISO/IEC 15504-2 and ISO/IEC 15504-3 specify the requirements and guidelines for performing the assessment of process capability. These requirements include the need for a documented assessment process, using the PAM which will be compatible with the reference model of ISO/IEC 15504-2 and applying the tools to support the assessment process as well as the responsibility of the competent assessors in the assessment process. The competent assessor provides the guidelines to the assessment team and moderates team judgments/ratings to ensure consistent interpretation. The competence of the competent assessor is judged according to their knowledge of the software process, their skill in the use of the standard ISO/IEC 15504, and personal attributes contributing to effective performance (ISO/IEC TR 15504-3:1998(E); Foegen \& Richter, 2003). The concept of the documented assessment process according to ISO/IEC 15504 is shown in Fig.4.

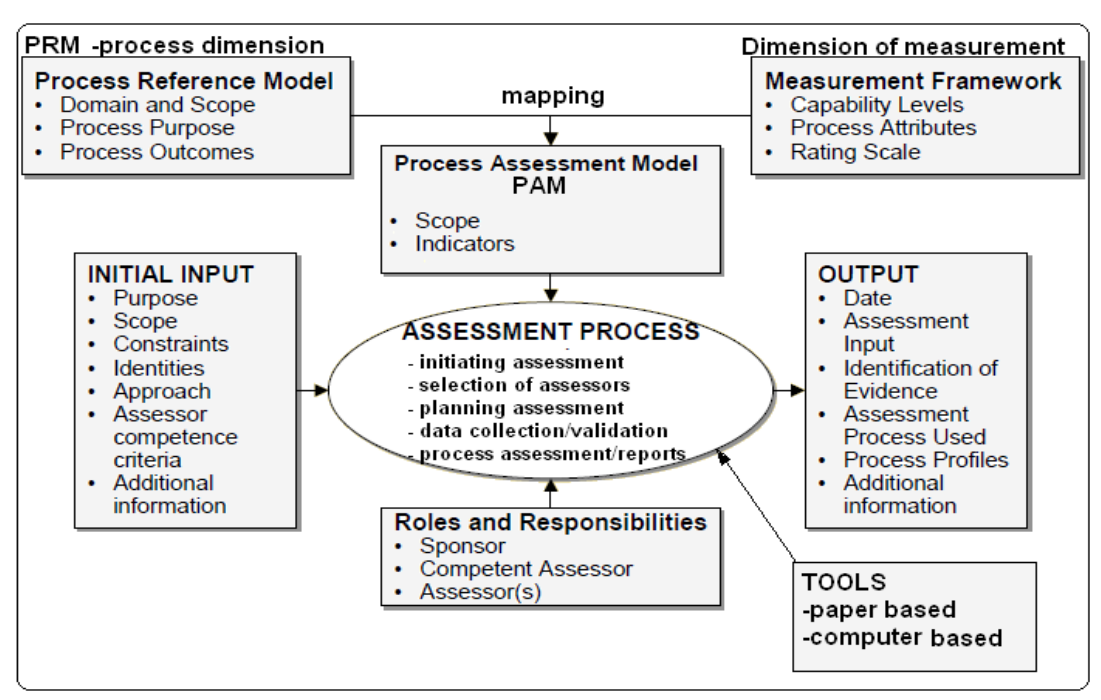

Fig. 4. The documented assessment process according to ISO/IEC 15504 (Foegen, 2003) 
Kozina, M. \& Kirinic, V.: Analyzing the Pam's Structure Using the Iso/Iec 15504-5...

\section{PAM's structure for software life cycle according to ISO/IEC 15504-5}

A concept of the software life cycle process assessment model is shown in Fig.5. This concept is compatible with the requirements of the ISO/IEC 15504-2 (shown in Fig.3) and presents the SPICE model (ISO/IEC TR 15504-5:1998(E)).

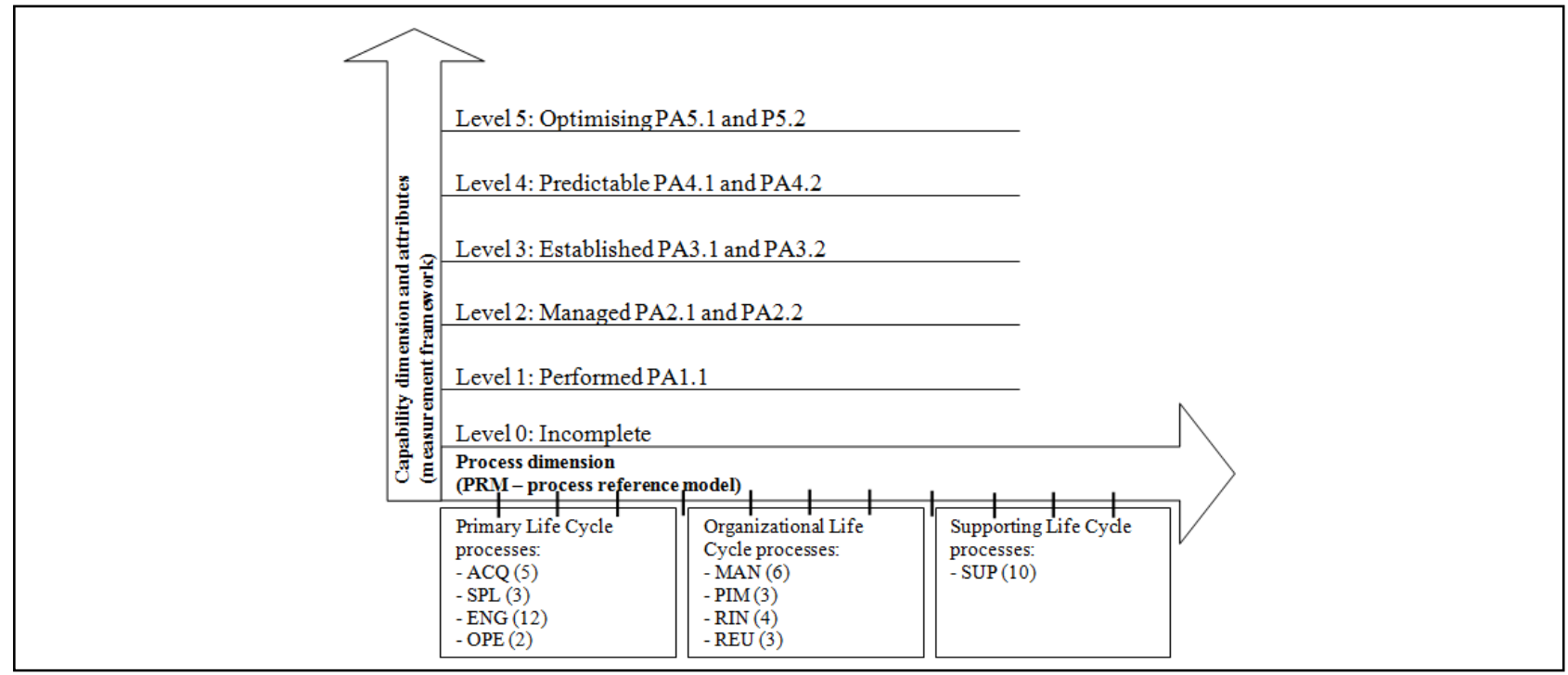

Fig. 5. PAM's structure for software life cycle

\subsection{Process dimension of the SPICE model}

Process dimension of the SPICE model is PRM and it was replaced with ISO/IEC 12207 amendments AMD1 (ISO/IEC TR 12207:1995/Amd 1: 2002) and AMD 2 (ISO/IEC TR 12207:1995/Amd 2: 2004). PRM includes three main categories of processes: Primary Life Cycle Processes, Organizational Life Cycle Processes and Support Life Cycle Processes (shown in Fig.6).

\subsection{Capability Dimension and Attributes (Measurement Framework)}

Each process of the SPICE model can be individually assessed through the range of 6 capability levels (ISO/IEC TR 15504-2:1998(E); Duncan, 2012):

- Level 0: Incomplete - the process has not been implemented or has failed in its purpose (partially executed). There are no attributes.

- Level 1: Performed - the process is implemented and executed its purpose. There is one attribute, Process Performance (PA 1.1).

- Level 2: Managed - the process executes its purpose (level 1) and manages its execution (the process is planned, monitored, adjusted). There are two attributes, Performance Management (PA 2.1) and Work Product Management (PA 2.2).

- Level 3: Established - managed process (level 2) is now implemented as a defined and documented process that is able to achieve the work results. There are two attributes, Process Definition (PA 3.1) and Process Deployment (PA 3.2).

- Level 4: Predictable - defined process (level 3) achieves its outcomes within the defined control limits. The process is controlled and must be predictable. There are two attributes, Process Measurement (PA 4.1) and Process Control (PA 4.2). 
- Level 5: Optimizing - predictable process (level 4) is continuously improving in order to achieve business objectives of the organization. There are two attributes, Process Innovation (PA 5.1) and Process Optimization (PA 5.2).

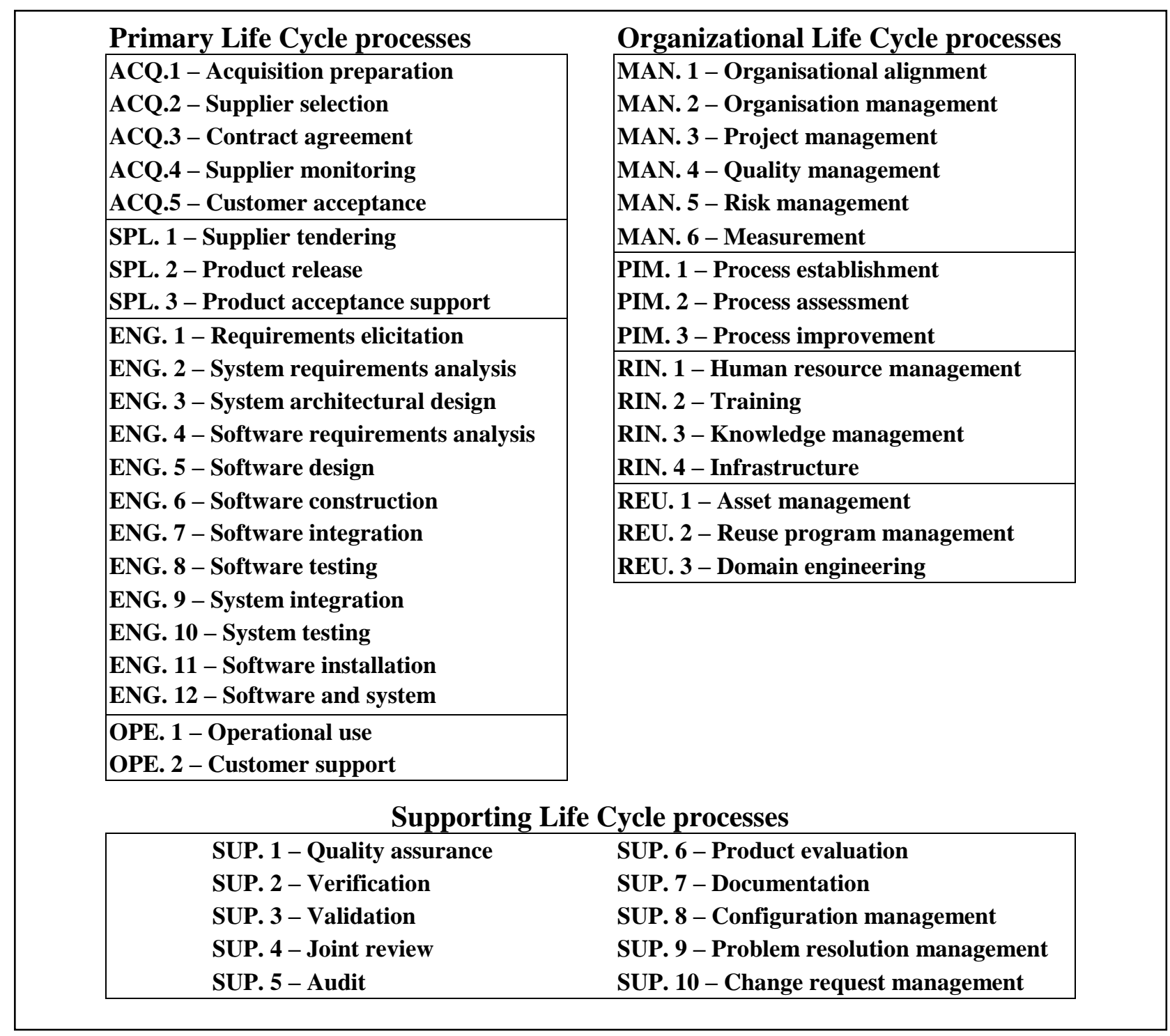

Fig. 6. Process areas of the SPICE model

\section{Assessment of the process capabilities using the SPICE model in the software organization}

This chapter describes the procedure of the capability assessment for the primary processes, organizational processes and supporting processes within the specific software organization. Its main activity is computer programming and it has about 20 employees. The procedure of the capability assessment was described in detail in the paper only for the Configuration Management process area. However, the same procedure of the assessment was applied on the other processes of SPICE model and the overall results are analyzed in the paper. The authors used different SPI software tools (such as Appraisal Assistant tool Beta 3 v2.0.9, SPICE 1-2-1, etc.) to support the assessment process. The work products and the base practices of each 
process area were used as the assessment indicators for the attribute PA1.1. The generic practices were used as the assessment indicators for the other attributes such as PA2.1, PA2.2, PA3.1, PA3.2, PA4.1, PA4.2, PA5.1 and PA5.2.

\subsection{Assessment of the Configuration Management capability according to the PA1.1 attribute}

The purpose of the Configuration Management process is to establish and maintain the integrity of the work products/items of a process or project and make them available to concerned parties.

We assess how the process area (i.e. Configuration Management) is capable of meeting outcomes according to the process performance attribute PA1.1 (Fig. 7).

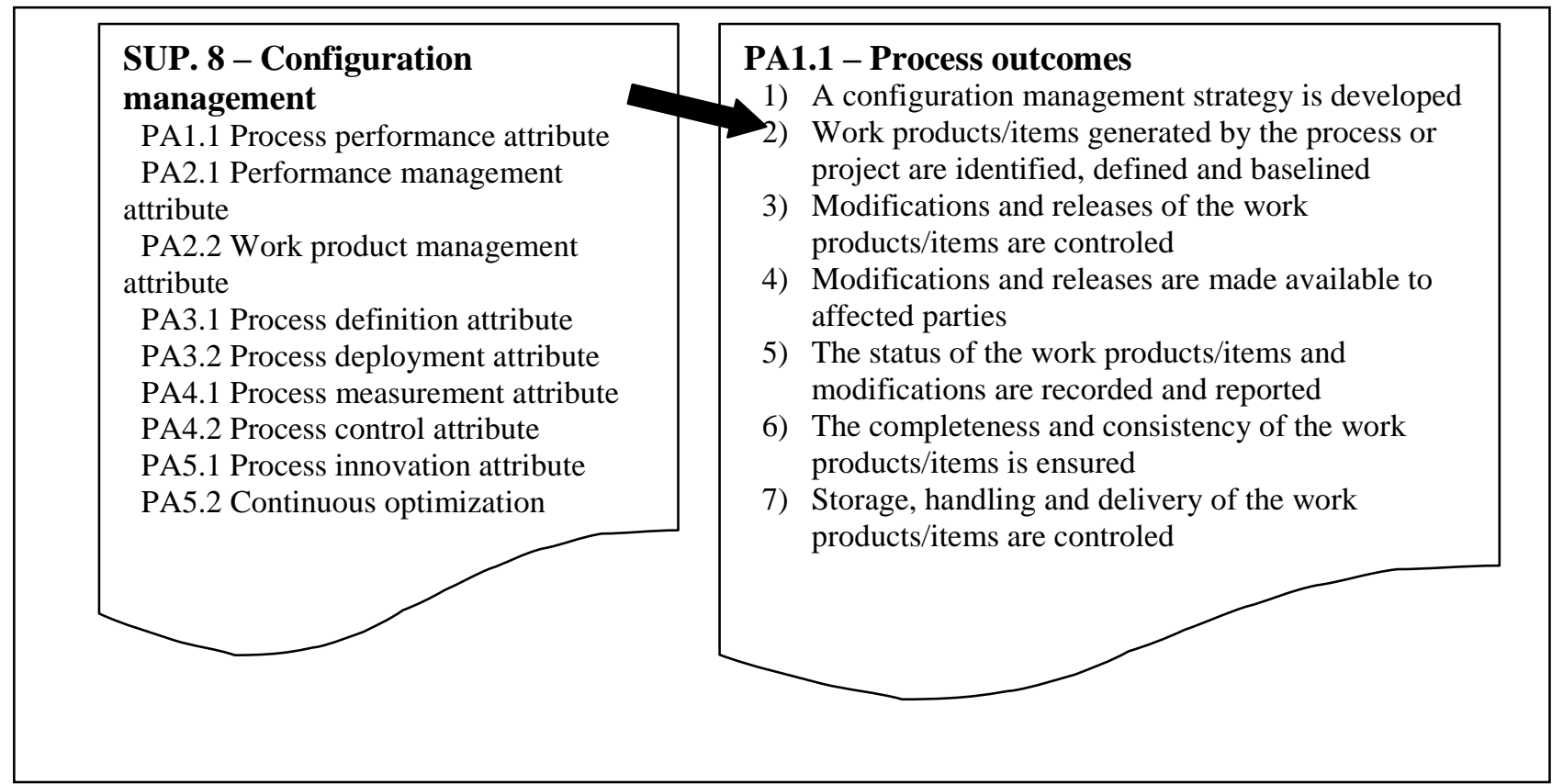

Fig. 7. Outcomes of the Configuration Management for PA1.1

The assessment indicators are the work products and the base practices (Fig. 8). Each of outcomes should be assessed according to these indicators. The outcome rating, depending on the assessment indicators and their strength and weaknesses, can be: not satisfied, partially satisfied, largely satisfied or fully satisfied.

The assessment of the first outcome of the Configuration Management based on the assessment indicators such as base practice (i.e. develop configuration management strategy) and related work product (i.e. configuration management plan) was conducted. According to the suggested rating scale mentioned above the first outcome is rated as fully satisfied (Tab. 2).

Following the same procedure other outcomes shall be assessed too in order to assess the capability of the Configuration Management process for the PA1.1 attribute. The assessment results for all 7 outcomes of this process are shown in Tab 2. Accordingly, we conclude that the PA1.1 attribute for the Configuration Management process was achieved. The Configuration Management process fully achieves its purpose. 


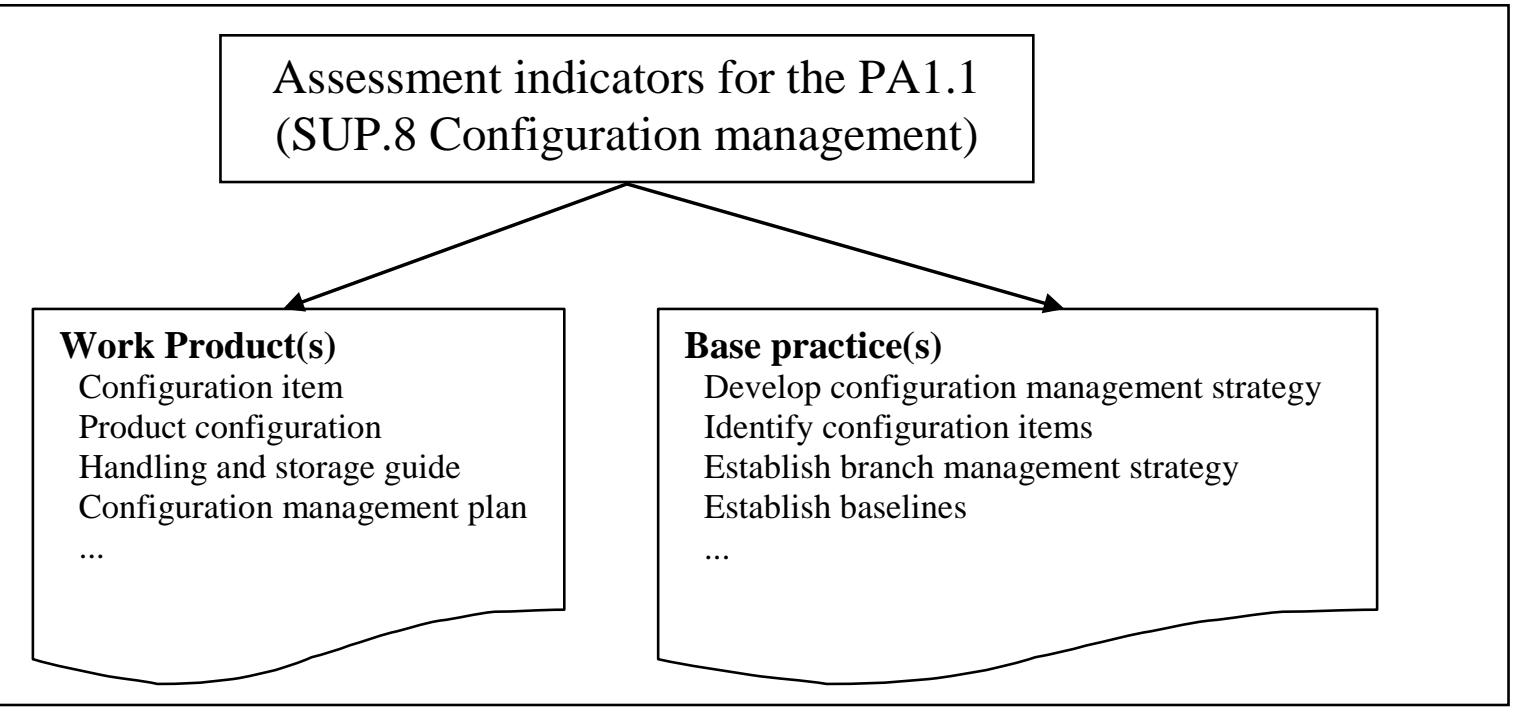

Fig. 8. Assessment indicators for the PA1.1 attribute for the Configuration Management process

\subsection{Assessment of the Configuration Management capability according to the other SPICE attributes}

The assessment of the Configuration Management process within the higher level of capability is conducted using the attributes from PA2.1 to PA5.2 and defined achievements. In general, each achievement is assessed using the assessment indicators such as generic practices, generic resources and generic work products. In our assessment process, we used the generic practices as the indicators for each process attribute. The same indicators have been applied to other processes of the SPICE model. Process Attribute Rating for PA2.1 is shown in Tab. 2. According to the obtained results, we can conclude that the Configuration Management process has the defined plans and objectives for its performance as well as the relevant monitoring, responsibilities, resources. Some of the achievements (assessed largely satisfied) should be improved. Assessment indicators, used for PA2.1, are the following generic practices: Identify the objectives for the performance of the process; Plan and monitor the performance of the process to fulfil the identified objectives; Control the performance of the process; Define responsibilities and authorities for performing the process; Identify and make available resources to perform the process according to plan; Manage the interfaces between involved parties.

Process Attribute Rating for PA2.2 is shown in Tab.2. According to the obtained results, we can conclude that the Configuration Management process has the defined requirements for their work products, their documentation and control. Assessment indicators, used for PA2.2, are the following generic practices: Define the requirements for the work products; Define the requirements for documentation and control of the work products; Identify, document and control the work products; Review and adjust work products.

Process Attribute Rating for PA3.1 is shown in Tab.2. According to the obtained results, we can conclude that the Configuration Management process uses definition of the standard process and has the defined roles and required infrastructure for its 
Kozina, M. \& Kirinic, V.: Analyzing the Pam's Structure Using the Iso/Iec 15504-5...

performance. Assessment indicators, used for PA3.1, are the following generic practices: Define the standard process that will support the deployment of the defined process; Determine the sequence and interaction between processes so that they work as an integrated system of processes; Identify the roles and competencies for performing the standard process; Identify the required infrastructure and work environment for performing the process; Determine suitable methods to monitor the effectiveness and suitability of the process.

Process Attribute Rating for PA3.2 is shown in Tab.2. According to the obtained results, we can conclude that the Configuration Management process achieves its purpose as the standard and documented process. Assessment indicators, used for PA3.2, are the following generic practices: Deploy a defined process that satisfies the context specific requirements of the use of the standard process; Assign and communicate roles, responsibilities and authorities for performing the defined process; Ensure necessary competencies for performing the defined process; Provide resources and information to support the performance of the defined process; Provide adequate process infrastructure to support the performance of the defined process; Collect and analyze data about performance of the process to demonstrate its suitability and effectiveness.

The assessment of all other Process Attributes are also shown in Tab.2. According to the obtained results for PA4.1, we can conclude that the Configuration Management process has no defined quantitative objectives/measures for the performance, so all practices related to PA4.1 are poorly implemented.

According to the obtained results for PA4.2, it is obviously that the Configuration Management process has no implemented practices of the quantitative management.

The obtained results of the assessment for PA5.1 show that the Configuration Management process has partially implemented practices for the process improvement and innovation.

And finally, according to the obtained results for PA5.2, we can conclude that the Configuration Management process has no implemented practices for the business process redesign due to the objectives of the process improvement and innovation.

After completing the assessment procedure, the Configuration Management process has the existing capability level $\mathrm{CL}=3$. This is the level of the defined and documented process. Due to the further improvement of the process, it is necessary to implement a generic practice for quantitative process management (PA4.1 and PA4.2) and generic practices for implementing changes and innovative process improvement (PA5.1 and PA5.2). Tab. 3 shows the results of the comprehensive capability assessment of the Configuration Management process. 
ISO 15504-5 Process: SUP. 8 Configuration management Process outcomes/ Process attribute achievements Process Attribute: PA1.1 Process Performance attribute

A configuration management strategy is developed

Work products/items generated by the process or project are identified, defined and baselined

Modifications and releases of the work products/items are controlled

Modifications and releases are made available to affected parties

The status of the work products/items and modifications are recorded and reported

The completeness and consistency of the work products/items is ensured

Storage, handling and delivery of the work products/items are controlled

Process Attribute: PA2.1 Performance management attribute

Objectives for the performance of the process are identified

Performance of the process is planned and monitored

Performance of the process is adjusted to meet plans

Responsibilities and authorities for performing the process are defined, assigned and communicated

Resources and information necessary for performing the process are identified, made available, allocated and used

Interfaces between the involved parties are managed to ensure both effective communication and also clear assignment of responsibility

\section{Process Attribute: PA2.2 Work product management attribute}

Requirements for the work products of the process are defined

Requirements for documentation and control of the work products are defined

Work products are appropriately identified, documented, and controlled

Work products are reviewed in accordance with planned arrangements and adjusted as necessary to meet requirements

\section{Process Attribute: PA3.1 Process definition attribute}

A standard process, including appropriate tailoring guidelines, is defined that describes the fundamental elements that must be incorporated into a defined process

The sequence and interaction of the standard process with other processes are determined

Required competencies and roles, for performing a process are identified as part of the standard process

Required infrastructure and work environment for performing a process are identified as part of the standard process

Suitable methods for monitoring the effectiveness and suitability of the process are determined

\section{Process Attribute: PA3.2 Process deployment attribute}

A defined process is deployed based upon an appropriately selected and/or tailored standard process

Required roles, responsibilities and authorities for performing the defined process are assigned and communicated

Personnel performing the defined process are competent on the basis of appropriate education, training, and experience

Required resources and information necessary for performing the defined process are made available, allocated and used

Required infrastructure and work environment for performing the defined process are made available, managed and maintained

Appropriate data are, collected and analysed as a basis for understanding the

behaviour of, and to demonstrate the suitability and effectiveness of the process, and to evaluate where continuous improvement of the process can be made

Tab. 2. Capability Level assessment for the process Configuration Management 


\begin{tabular}{|c|c|c|c|c|}
\hline $\begin{array}{l}\text { ISO 15504-5 Process: SUP. } 8 \text { Configuration management } \\
\text { Process outcomes/ Process attribute achievements }\end{array}$ & 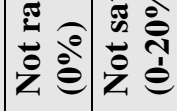 & 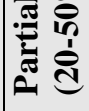 & 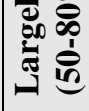 & 主高 \\
\hline Process Attribute: PA4.1 Process measurement attribute & $\mathrm{X}$ & & & \\
\hline Process information needs in support of relevant business goals are established & & $\mathrm{X}$ & & \\
\hline $\begin{array}{l}\text { Process measurement objectives are derived from identified process information } \\
\text { needs }\end{array}$ & & $\mathrm{X}$ & & \\
\hline $\begin{array}{l}\text { Quantitative objectives for process performance in support of relevant business goals } \\
\text { are established }\end{array}$ & $\mathrm{X}$ & & & \\
\hline $\begin{array}{l}\text { Measures and frequency of measurement are identified and defined in line with } \\
\text { process measurement objectives and quantitative objectives for process performance }\end{array}$ & $\mathrm{X}$ & & & \\
\hline $\begin{array}{l}\text { Results of measurement are collected, analysed and reported in order to monitor the } \\
\text { extent to which the quantitative objectives for process performance are met }\end{array}$ & $\mathrm{X}$ & & & \\
\hline Measurement results are used to characterise process performance & & $\mathrm{X}$ & & \\
\hline Process Attribute: PA4.2 Process control attribute & $\mathrm{X}$ & & & \\
\hline Suitable analysis and control techniques where applicable, are determined and applied & $\mathrm{X}$ & & & \\
\hline Control limits of variation are established for normal process performance & $\mathrm{X}$ & & & \\
\hline Measurement data are analysed for special causes of variation & & $\mathrm{X}$ & & \\
\hline Corrective actions are taken to address special causes of variation & & $\mathrm{X}$ & & \\
\hline Control limits are re-established (as necessary) following corrective action & $\mathrm{X}$ & & & \\
\hline Process Attribute: PA5.1 Process innovation attribute & $\mathrm{X}$ & & & \\
\hline $\begin{array}{l}\text { Process improvement objectives for the process are defined that support the relevant } \\
\text { business goals }\end{array}$ & & $\mathrm{X}$ & & \\
\hline $\begin{array}{l}\text { Appropriate data are analysed to identify common causes of variations in process } \\
\text { performance }\end{array}$ & $\mathrm{X}$ & & & \\
\hline $\begin{array}{l}\text { Appropriate data are analysed to identify opportunities for best practice and } \\
\text { innovation }\end{array}$ & & $\mathrm{X}$ & & \\
\hline $\begin{array}{l}\text { Improvement opportunities derived from new technologies and process concepts are } \\
\text { identified }\end{array}$ & & $\mathrm{X}$ & & \\
\hline $\begin{array}{l}\text { An implementation strategy is established to achieve the process improvement } \\
\text { objectives }\end{array}$ & $\mathrm{X}$ & & & \\
\hline Process Attribute: PA5.2 Continuous optimization attribute & $\mathrm{X}$ & & & \\
\hline $\begin{array}{l}\text { Impact of all proposed changes is assessed against the objectives of the defined } \\
\text { process and standard process }\end{array}$ & $\mathrm{X}$ & & & \\
\hline $\begin{array}{l}\text { Implementation of all agreed changes is managed to ensure that any disruption to the } \\
\text { process performance is understood and acted upon }\end{array}$ & $\mathrm{X}$ & & & \\
\hline $\begin{array}{l}\text { Effectiveness of process change on the basis of actual performance is evaluated } \\
\text { against the defined product requirements and process objectives to determine whether } \\
\text { results are due to common or special causes }\end{array}$ & $\mathrm{X}$ & & & \\
\hline
\end{tabular}

Tab. 2(cont.). Capability Level assessment for the process Configuration Management

Process Capability Rating for the whole group of Support Life Cycle processes is shown in Fig.9. In accordance with the assessment, it can be concluded that the average level of capability for the processes corresponding to level 2 (Managed).

Software organization must improve the level of process capabilities such as Quality Assurance (SUP.1), Audit (SUP.5) Documentation (SUP.7), and to deploy their base and generic practices. Generally, the organization should implement and improve the practices of the quantitative management and process optimization.

Process Capability Rating for the whole group of Primary Life Cycle processes is shown in Fig.10. In accordance with the assessment, it can be concluded that the average level of capability for the processes also corresponding to level 2 
(Managed). Software organization must implement improvements in almost all processes (Acquisition Process Group, Supply Process Group, Process Engineering Group, and Operation Process Group).

\begin{tabular}{|c|c|c|c|c|c|}
\hline $\begin{array}{l}\text { ISO 15504-5 Process: SUP. } 8 \text { Configuration management } \\
\text { Process outcomes/ Process attribute achievements }\end{array}$ & 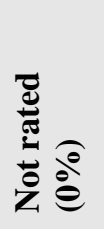 & 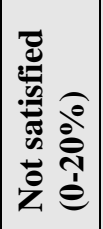 & 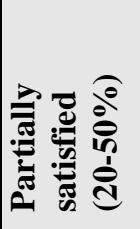 & 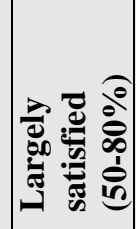 & 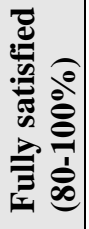 \\
\hline Process Attribute: PA1.1 Process Performance attribute & & & & & $\mathrm{X}$ \\
\hline Process Attribute: PA2.1 Performance management attribute & & & & & $\mathrm{X}$ \\
\hline Process Attribute: PA2.2 Work product management attribute & & & & & $\mathrm{X}$ \\
\hline Process Attribute: PA3.1 Process definition attribute & & & & & $\mathrm{X}$ \\
\hline Process Attribute: PA3.2 Process deployment attribute & & & & & $\mathrm{X}$ \\
\hline Process Attribute: PA4.1 Process measurement attribute & & $\mathrm{X}$ & & & \\
\hline Process Attribute: PA4.2 Process control attribute & & $\mathrm{X}$ & & & \\
\hline Process Attribute: PA5.1 Process innovation attribute & & $\mathrm{X}$ & & & \\
\hline Process Attribute: PA5.2 Continuous optimization attribute & & $\mathrm{X}$ & & & \\
\hline
\end{tabular}

Tab. 3. Comprehensive capability assessment of the Configuration Management Process: Level 3 - Defined

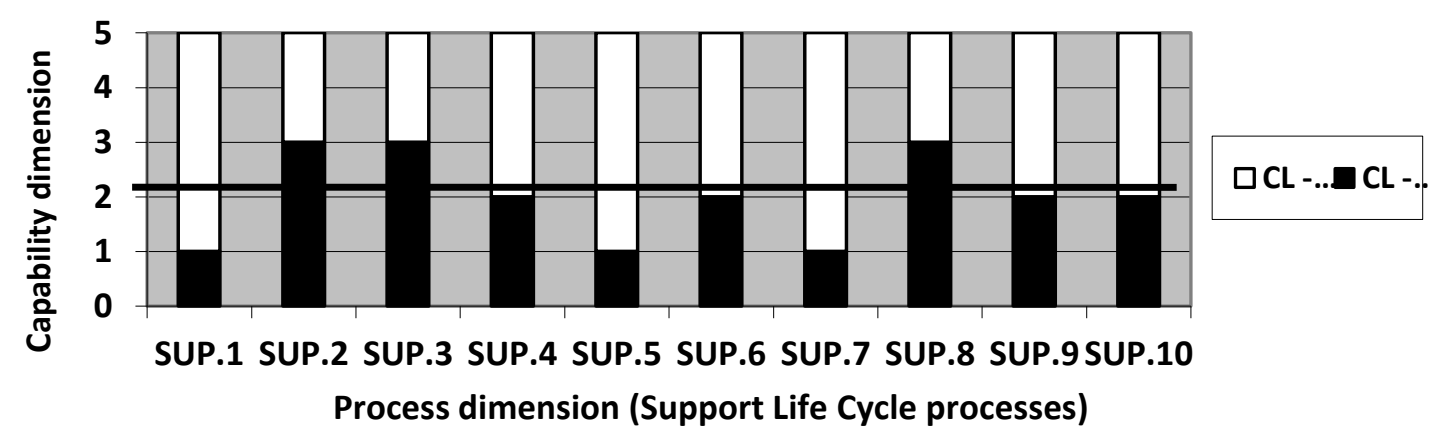

Fig. 9. Process Capability Rating for the Supporting Life Cycle processes

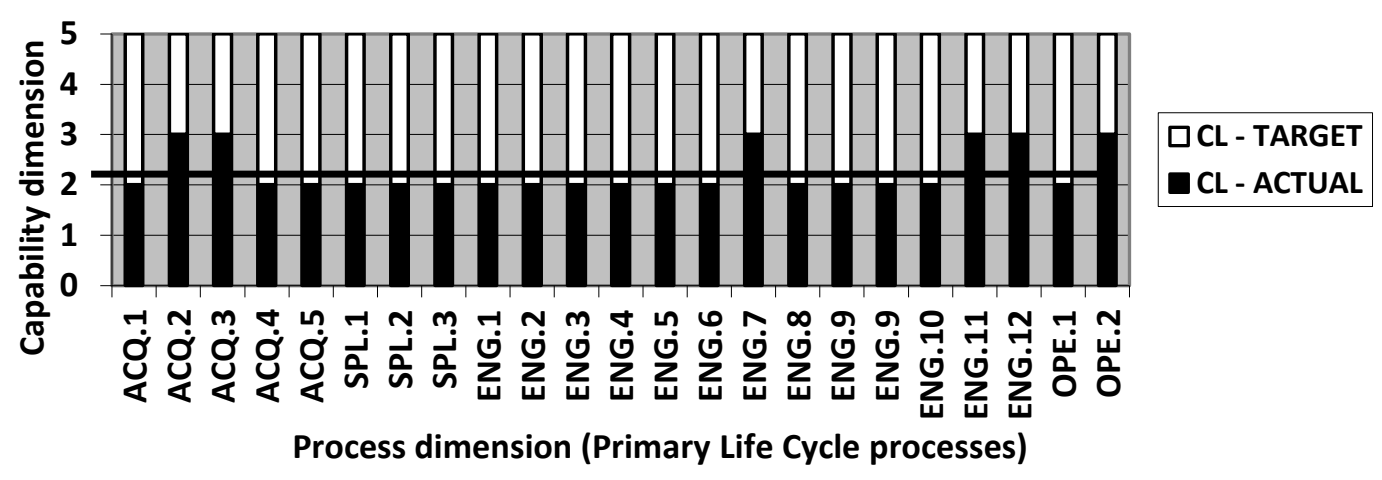

Fig. 10. Process Capability Rating for the Primary Life Cycle processes

Process Capability Rating for the whole group of Organizational Life Cycle processes is shown in Fig.11. This is the weakest category of process areas due to the process capability level (average level $\mathrm{CL}=1$, Performed). The organization should 
Kozina, M. \& Kirinic, V.: Analyzing the Pam's Structure Using the Iso/Iec 15504-5...

implement improvements especially in the process groups such as Organizational Alignment (MAN1), Organization Management (MAN2), Project Management (MAN 3), Risk Management (MAN 5), Measurement (MAN 6), Process Establishment (PIM 1), Process Assessment (PIM 2), Process Improvement (PIM 3), Knowledge Management (RIN 3), and Asset management (REU 1).

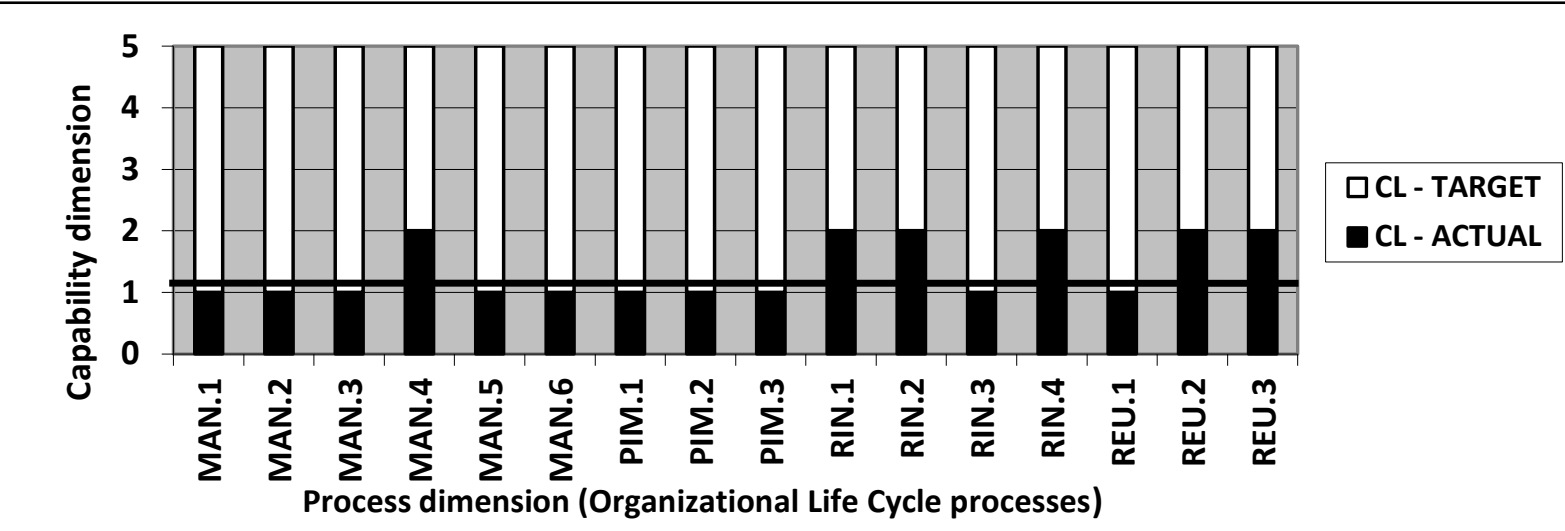

Fig.11. Process Capability Rating for the Organizational Life Cycle processes

Due to the obtained results from this assessment, we can conclude that the software organization has the existing maturity level $\mathrm{ML}=2$ (Managed). The organization should implement the improvements described above in relation with the business goals in order to raise the existing maturity level (from $M L=2$ to $M L=3$ ).

\section{Software tools to support software process assessment}

There are software tools to support software process assessment based on different SPI models such as Appraisal Assistant tool Beta 3 (Appraisal Assistant Beta, 2013), SPICE 1-2-1 (SPICE 1-2-1 for the International Standard ISO/IEC IS 15504:2012, 2013), etc.

An example of a software tool to support the assessment or appraisal of process capability or organizational maturity is the Appraisal Assistant (Appraisal Assistant Beta) - a software application developed by the Software Quality Institute at the Griffith University. Assessments using Appraisal Assistant follow approaches consistent with the requirements of ISO/IEC 15504 - Information technology: Process assessment and the Assessment Requirements for CMMI, and are evidencedriven (An Overview of Appraisal Assistant, 2013).

The functionalities of the Appraisal Assistant tools involve:

- user management,

- organizations to be assessed data management (creation of organizations' profiles),

- appraisal management (to support two main appraisal projects: CMMI and ISO 15504 appraisal projects and enable the user to customize Organization Scope, Process scope and Appraisal Team), 
- evidence management (Appraisal Assistant creates one evidence registry for each appraisal project; each evidence record can be associated to one or more model practices as implementation indicators);

o for CMMI appraisal it enables the user to realize: CMMI Model Practice characterization, CMMI Goal rating, CMMI Process area rating, Organization unit maturity rating, Review CMMI appraisal results;

o for ISO 15504 appraisal: each evidence record can be associated to one or more assessment indicators; the evidences are automatic associated to process outcome/attribute achievement according to the standard assessment model's indicator to outcome/achievement relationships; the evidences in the performance dimension are: Work Product - Base Practice, the evidences in the capability dimension are: Work Product - Generic Practice - Generic Resource; the Appraisal Assistant tool enables the user: to characterize the satisfaction of each process outcome/attribute achievement and record observations through the all process attributes (PA1.1-PA5.2); to get ISO15504 Process Attribute Rating; to get ISO15504 Process Capability Rating; to review ISO15504 Assessment Results

- and maintenance (in User Management, Standard Appraisal Model Management, Model Mapping Manager for Manage CMMI to ISO 9001/ISO 15504 Mappings).

\section{Conclusion}

In today's software industry, the quality of software is very often questionable. The strategic goal for the software organizations is how to improve the quality of software by applying different standards, methods, models, tools that enable the software development based on the best practices of the integrated process and product development as well as the approaches for the maturity assessment of such practices. Accordingly, it is possible to determine the required improvements for the software development.

To address the problem, emphasized above, the authors in the paper were analyzed one of the model for improving software quality. It was the Process Assessment Model (PAM) for software within the ISO/IEC 15504-5 standard. Using this model, the authors conducted the capability assessment for the Primary Life Cycle processes, Organizational Life Cycle processes and Supporting Life Cycle processes within specific software organization in Croatian business practice. According to the obtained results, the whole organizational maturity level is no greater then 2 - Managed Level: the processes execute their purposes (Level 1) and manage their execution (each of the processes is planned, monitored, adjusted). The organization should implement improvements in all processes, especially in the Organizational Life Cycle processes and achieve the organizational maturity at least level 3.The implementation of such processes and improvements need to invest a lot of resources and it is very expensive. The management support is very important in this decision making process.

The applied PAM's structure (SPICE model) within our research is very effective since it integrates the best practices based on integrated process and product development as well as the approaches for the maturity assessment of these practices. However, this model is still developing and can be easily integrated with other 
Kozina, M. \& Kirinic, V.: Analyzing the Pam's Structure Using the Iso/Iec 15504-5...

models, not only for the software process improvement, but also for the development of the complex IT systems and IT services. This is the subject of the future researches.

\section{References}

*** An Overview of Appraisal Assistant, (2013). Software Quality Institute, Griffith University, Available from: http://www.sqi.griffith.edu.au/AppraisalAssistant/ AppraisalAssistantDemo.ppt, Accessed: 2013-02-13

*** Appraisal Assistant Beta, (2013). Software Quality Institute, Griffith University, Available from: http://www.sqi.griffith.edu.au/AppraisalAssistant/about.html, Accessed: 2013-02-13

*** ISO/IEC TR 12207:1995, (1995). Information technology - Software life cycle processes, ISO/IEC JTC 1/SC 7

*** ISO/IEC TR 12207:1995/Amd 1: 2002, (2002). Information technology Software life cycle processes, ISO/IEC JTC 1/SC 7

*** ISO/IEC TR 12207:1995/Amd 2: 2004, (2004). Information technology Software life cycle processes, ISO/IEC JTC 1/SC 7

*** ISO/IEC TR 15504-1:1998(E), (1998). Information technology - Software process assessment - Part 1: Concepts and introductory guide, ISO/IEC JTC 1/SC 7

*** ISO/IEC TR 15504-2:1998(E), (1998). Information technology - Software process assessment - Part 2: A reference model for processes and process capability, ISO/IEC JTC $1 / S C 7$

*** ISO/IEC TR 15504-3:1998(E), (1998). Information technology - Software process assessment - Part 3: Performing an assessment, ISO/IEC JTC 1/SC 7

*** ISO/IEC TR 15504-5:1998(E), (1998). Information technology - Software process assessment - Part 5: An assessment model and indicator guidance, ISO/IEC JTC $1 / S C 7$

*** SPICE 1-2-1 for the International Standard ISO/IEC IS 15504:2012, (2013). $H M \& S \quad I T$-Consulting GmbH, Available from: http://www.spice121.com/english/default.htm, Accessed: 2013-02-13

/Sp13/811/Lectures/Misc/cmmi.pdf, Accessed: 2013-02-13

Duncan, S.P. (2012). Making Sense of ISO 15504 (and SPICE), Available from: http://www.westfallteam.com/sites/default/files/papers/Making_Sense_of_15504.pdf, Accessed: 2013-02-13

Foegen, M. (2003). Informationen von der ISO 15504 Working Group, Available from:http://www.wibas.de/download/Informationen_von_der_ISO_15504_Working_ Group.pdf, Accessed: 2013-02-13

Foegen,M. \& Richter, J. (2003). CMM, CMMI and ISO 15504 (SPICE), Wibas $\mathrm{GmbH}$ IT Maturity Services, Available from: http://people.eecs.ku.edu/ $\sim$ saiedian/Teaching

O'Regan, G. (2011). Introduction to Software Process Improvement, SpringerVerlag, ISBN 978-0-85729-171-4, London

Sassenburg H. \& Kitson, D. (2006). A comparative analysis of CMMI and automotive SPICE, Available from: http://www.se-cure.ch/images/06-ESEPG1.pdf, Accessed: 2013-02-13 